International Journal of Engineering \& Technology, $7(2.12)(2018) 214-218$
SPC

\title{
Power quality problems mitigation using dynamic voltage restorer (DVR) with pi controller and fuzzy logic controller
}

\author{
Tejaswini Sarwade $^{1 *}$, V.S. Jape ${ }^{2}$, D. G. Bharadwaj ${ }^{3}$ \\ ${ }^{1}$ Tejaswini Sarwade is with the P.E.S. 's Modern College of Engineering, Pune, 411005, India. \\ ${ }^{2}$ V. S. Jape is with P.E.S.'s Modern College of Engineering, Pune, 411005, India \\ ${ }^{3}$ D. G. Bharadwaj is with Bharati Vidyapith Deemed University College of Engineering, Pune \\ *Corresponding author E-mail: sarwadet@gmail.com
}

\begin{abstract}
The existence of non-standard currents, frequencies and voltages enhances the Power Quality (PQ) problems. Power consumed by the consumers and losses occurred in power system are deciding factors for the utility to determine the performance of the power system in terms of Power Quality. These Power Quality problems lead to failure of end user equipments as well as creates disturbances in power distribution network, thereby deteriorates residual life assessment of major equipments used in substation. The PQ problems can be characterized as voltage surges, sags, swells, harmonic distortions, etc. There are many reasons for the determination of Power Quality. The loads used by the consumers of electricity abnormally leads to deprove the Power Quality. Low power factor loads are taken care of by the utilities in the form of financial penalty. However, occurrence of harmonics, voltage swells and sags in the system is the most powerful reason behind degradation of Power Quality. To mitigate these issues, use of Custom Power Devices (CPD) in the distribution network is the most significant solution. Paper presents the design of the CPD like Dynamic Voltage Restorer (DVR) using two control strategies i.e. PI Controller and Fuzzy Logic Controller (FLC). MATLAB/SIMULINK is used to analyze the effectiveness of these control strategies.
\end{abstract}

Keywords: Power Quality; Voltage Sag; Voltage Swell; Custom Power Devices (CPD); Dynamic Voltage Restorer (DVR); PI Controller; Fuzzy Logic Controller.

\section{Introduction}

Electrical energy plays an important role in day-to-day's life. Therefore handling of energy in bulk is a very complex task so that critical analysis of energy in power system is a paramount activity. Utilization of energy increased due to industrial, commercial, domestic customers, ultimately known as prime factor to decide the standardization and development stage of the country. Deterioration of Power Quality is caused due to use of various non-linear loads in power distribution system. Thus Power Quality is determined by the performance and productivity of customer's equipment as well as huge financial losses to commercial and industrial customers.

There are many reasons for the determination of Power Quality. The loads used by the consumers of electricity abnormally leads to deprove the power quality. Low power factor loads are taken care of by the utilities in the form of financial penalty. Considering the facts, electric utility must be able to evaluate, characterize and access the system performance to plan the system improvements for satisfying the Power Quality needs [1]. But no such corrective measures are provided for harmonic distortions by the utility. Thus it becomes of priority to take into account the effect of harmonic distortions.

\section{Power quality parameters}

Any failure in voltage, current or frequency is accounted as a harmonic distortions, transients, voltage spikes, voltage sags, swells, fluctuations, are summed up as Power Quality problems.

The IEEE standard 1159 defines the voltage sag as a decrease in root mean square voltage or current typically between 0.1 per unit to 0.9 per unit at the power frequency for a time interval 0.5 cycles to 1 minute. The fault clearing time lies in the range 3 to 30 cycles [2].

The increase in root mean square value of voltage at power frequency between 1.1 per unit to 1.8 per unit lasting for 0.5 cycles to 1 minute is identified as swell.

The harmonic distortions or the harmonics are identified by a steady state deviation in the ideal sine wave of the voltage or current waveforms.

The transients can be defined as the part of change in the variable which disappears during transition from one steady state to another. The systematic variation in the voltage envelope whose magnitude does not exceed the limits specified by ANSI C 84.1 is called as voltage fluctuations. The variations in the voltages lie in the range 0.9 to 1.1 per unit. 


\section{Power quality improvement by various methods}

Power Quality improvement is the utmost important task to eliminate effects of the Power Quality issues. Various conventional methods are available to mitigate the power quality issues likewise lightning arresters, harmonic filters, static switches, tap changing transformers and FACTS Controllers [3].

In addition to these methods, Dynamic Voltage Restorer is identified as the most efficient Custom Power Device to mitigate the Power Quality problems [4].The DVR finds its application in the distribution system. It is connected in series with the circuit on load side. DVR mainly injects voltage to system for regulating load side voltage scenario. It can be installed between supply and load feeder. In addition to voltage sag and swell compensations DVR can also mitigate the faults like harmonics, transients [5].

\section{Basic configuration of $\mathrm{dvr}$}

The DVR Comprises of three basic components as explained below:

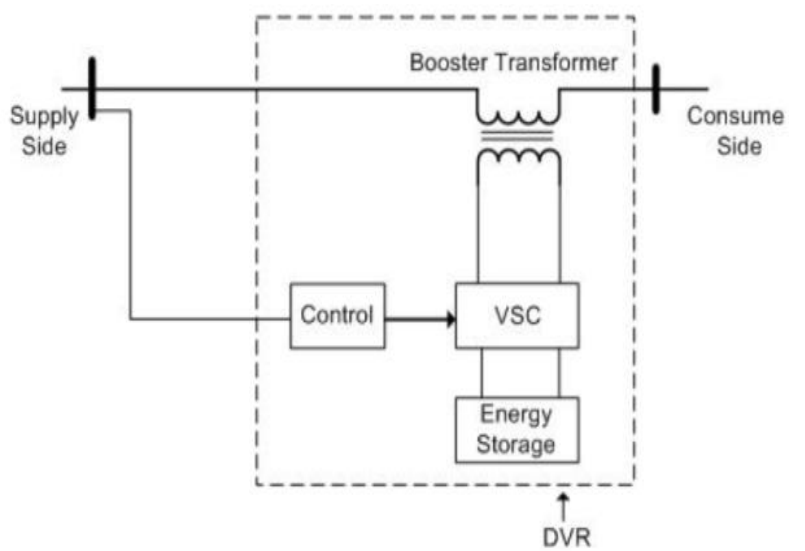

Fig. 1: Basic Block Diagram of Dynamic Voltage Restorer (DVR).

1) Booster Transformer

2) This transformer has a special design. The DVR is connected to the distribution side through its high-voltage winding. It serves the purpose of coupling the system voltage to compensation voltage. It limits coupling of noise and transients from one side to another.

3) Filter

It is used to filter out the output voltage of voltage source converter to reduce harmonics.

Voltage Source Converter (VSC)

It is simply a DC to AC Converter (inverter). It consists of energy storage unit and static switches. The VSC is used to generate sinusoidal voltage of required magnitude and phase at any frequency.

\section{Operation of DVR}

The basic function of the DVR is to inject a dynamically controlled voltage $\mathrm{V}_{\text {DVR }}$ into the system. Any effect that is caused due to the fault occurrence into the system is compensated by addition of this voltage.

There are two operating modes of DVR i.e. a) Standby mode and b) Boost mode. In standby mode, $\mathrm{V}_{\text {DVR }}$ is zero and the $\mathrm{LV}$ winding of booster transformer is shorted through the converter. Whenever the system shows normal operation DVR remains in standby mode. On actual detection of the fault, the DVR works in the boost mode where $\mathrm{V}_{\text {DVR }}$ becomes greater than 0 . In this mode, DVR injects the required voltage for compensation of sag.

The Thevenin's equivalent of DVR circuit is shown in Fig. 2.

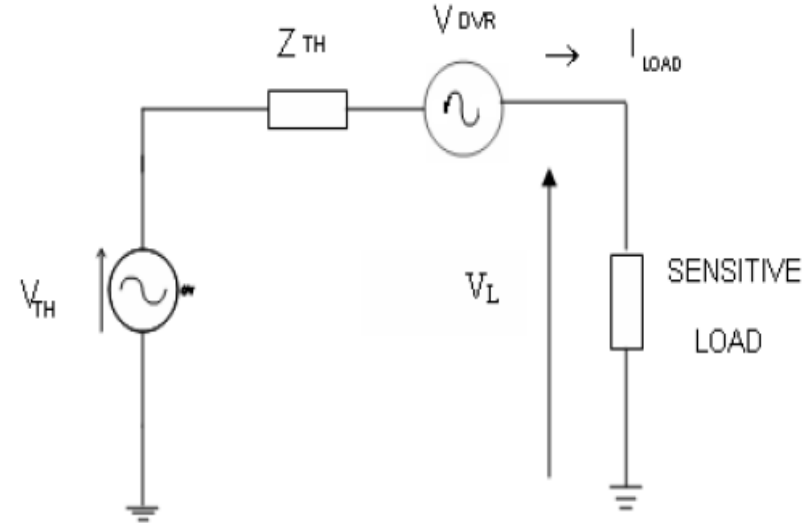

Fig. 2: Thevenin's Equivalent of DVR.

The voltage injected by DVR ( $\left.\mathrm{V}_{\mathrm{DVR}}\right)$ is given by,

$$
V_{D V R}=V_{L}+Z_{T H} \times I_{L}-V_{T H}
$$

Where, $\mathrm{V}_{\mathrm{L}}$ is desired Load Voltage;

$\mathrm{Z}_{\mathrm{TH}}$ is Thevenin's equivalent impedance;

IL is load current;

$\mathrm{V}_{\mathrm{TH}}$ is system voltage during fault

Load current is given by,

$$
I_{L}=\frac{P_{L}}{V}+j \frac{Q_{L}}{V}
$$

Load pf angle is calculated by,

$$
\theta=\tan ^{-1} \frac{Q_{L}}{P_{L}}
$$

Complex power injected by DVR is

$$
S_{D V R}=V_{D V R} \times I_{L}
$$

The active power is supplied by energy storage unit.

\section{Control methods of dvr}

From design and modeling point of view, control of DVR circuit topology is important factor. The control of DVR indicates the detection of any voltage disturbance using suitable detection techniques. The DVR performance is directly affected by performance of the voltage source converter only as it provides the reactive power required or the voltage support to the system. That's why inverter is considered as most important part of DVR topology [6] The inverter control strategies are generally classified as follows

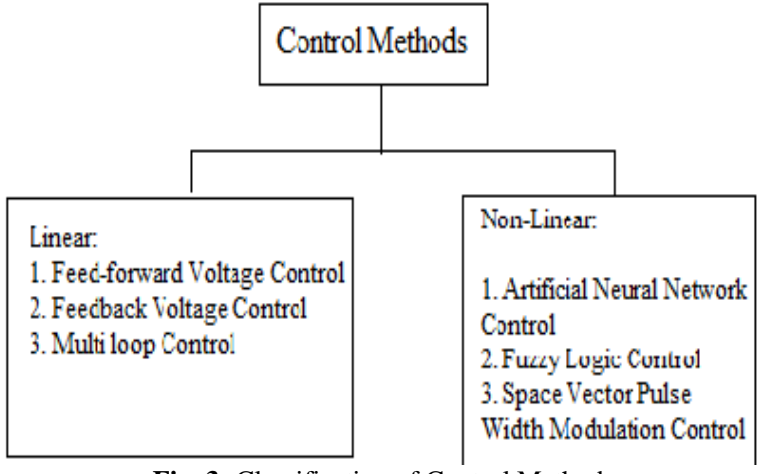

Fig. 3: Classification of Control Methods

\subsection{PI controller}


It is a linear feedback controller. Weighted sum of error and its integral value are prime factors to perform the control operation. The input to PI Controller is difference value between the system voltage signal and a reference voltage signal. The PI makes the adjustments in its proportional gain $\mathrm{K}_{\mathrm{p}}$ and integral gain $\mathrm{K}_{\mathrm{i}}$ so that the value of the steady state error is reduced to zero. The PI controller has simple structure but, the only disadvantage is that the gains are fixed.

The gating pulses are generated using the error signal. The control algorithm used is Park's Transformation. The three phase system voltages $\mathrm{V}_{\mathrm{a}}, \mathrm{V}_{\mathrm{b}}$ and $\mathrm{V}_{\mathrm{c}}$ are converted to dq0 rotating frame using following formula:

$$
\left[\begin{array}{c}
V_{d} \\
V_{q} \\
V_{\mathrm{o}}
\end{array}\right]=\left[\begin{array}{ccc}
\cos \theta & \cos \left(\theta-\frac{2 \Pi}{3}\right) & 1 \\
-\sin \theta & -\sin \left(\theta-\frac{2 \Pi}{3}\right) & 1 \\
0.5 & 0.5 & 0.5
\end{array}\right]\left[\begin{array}{c}
V_{a} \\
V_{b} \\
V_{c}
\end{array}\right]
$$

\subsection{Fuzzy logic controller}

It is a nonlinear control method and overcomes the drawbacks of PI controller. The fuzzy logic is multi-valued logic. It doesn't require any mathematical model of the given system. It is just required to define the flow of information into the system (control input variable), how it is processed (decision making) and the information flow out of the system (output variable). The Fuzzy Logic Controller (FLC) omits rigorous mathematical calculations. Fig. 4 Represents basic block diagram of Fuzzy Logic Controller

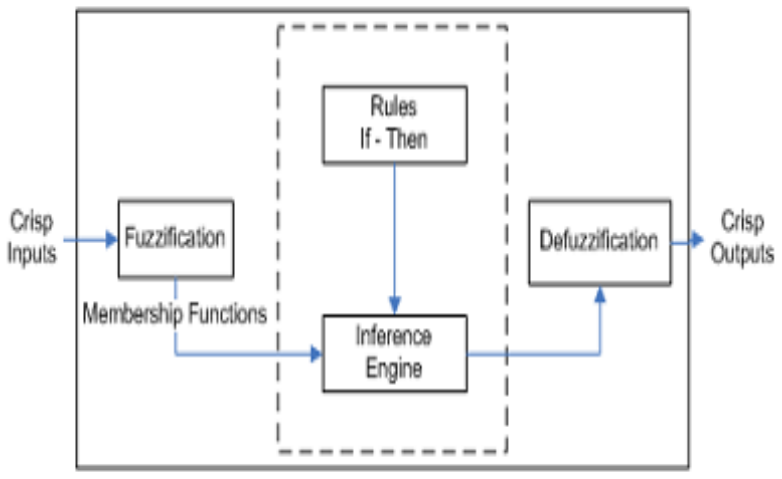

Fig. 4: Basic Block Diagram of FLC.

\subsection{Simulink models of dvr}

The system voltage is 3 -phase $400 \mathrm{~V}, 50 \mathrm{~Hz}$ supply. The load connected in the system is a three phase R-L load. The simulation is observed under the generation of voltage sag. The DVR serves the purpose of compensating the sag detected.

Fig. 5 represents the SIMULINK model for DVR with PI Controller. The fault resistance in all cases is kept $0.001 \mathrm{ohms}$ and reference voltage is considered as $300 \mathrm{~V}$.

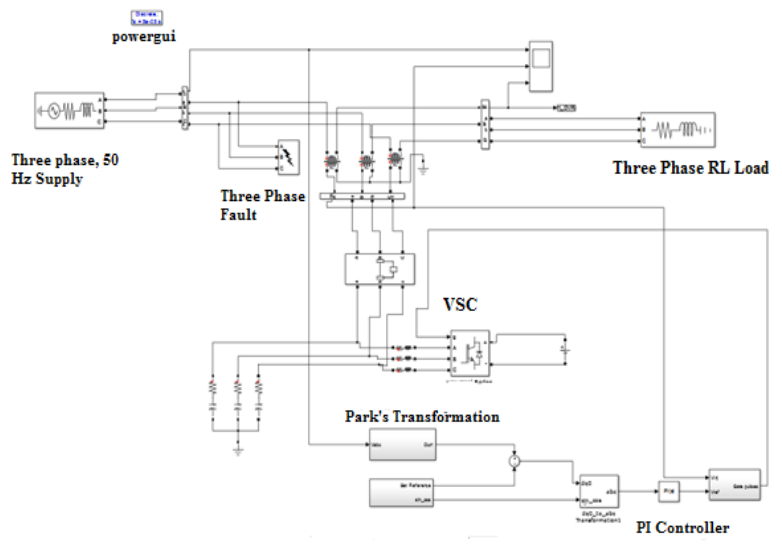

Fig. 5: Simulink Model of Dvr with Pi Controller.
Fig. 6 represents the SIMULINK model for DVR with FLC. Also the rule base to run the fuzzy operations is represented in tabular form in Table I

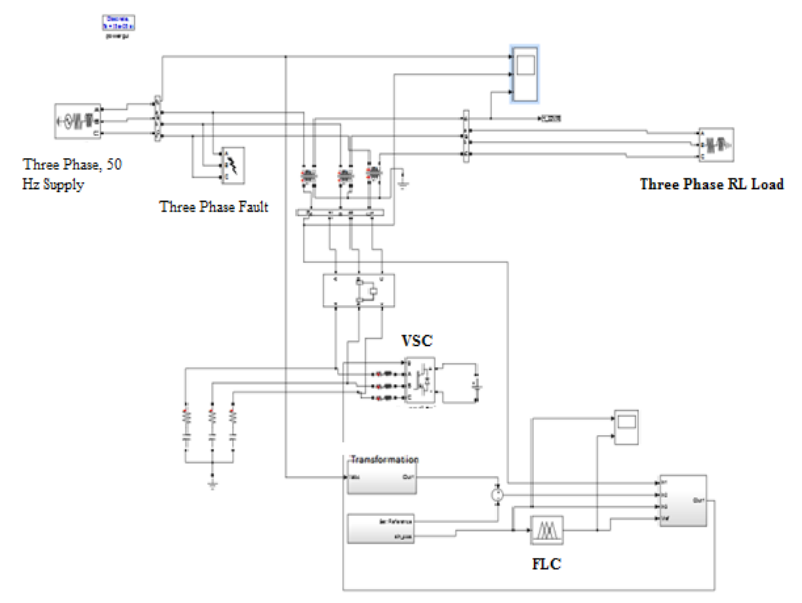

Fig. 6: SIMULINK Model of DVR with FLC.

\begin{tabular}{llll}
\multicolumn{4}{c}{ Table 1: Fuzzy Rule Base } \\
\hline Input $1 \rightarrow$ & $\mathrm{N}$ & $\mathrm{Z}$ & $\mathrm{P}$ \\
\hline Input2 $\downarrow$ & Output & & \\
N1 & NB & NS & Z \\
Z1 & NS & Z & Z \\
P1 & Z & PS & PB \\
\hline
\end{tabular}

\section{Results}

MATLAB/SIMULINK is used to analyze performance of system. The different faults such as L-G, L-L-G and L-L are introduced into system.

The simulation of the system under these faults is done without DVR. Then all other load conditions and fault resistance is kept the same and system is introduced with DVR. The DVR is implemented with two different controls such as PI Controller and FLC. The simulation waveforms of system voltage, DVR injected voltage into system on occurrence of voltage sag and the compensated load voltage are represented. The harmonics generation at every condition is observed using FFT analysis tool. The comparative analysis of the harmonic distortion values is done to analyze DVR performance under different control strategies.

L-G Fault

The system is introduced with L-G Fault, the occurrence of the voltage sag is observed. The sag is between duration $0.4 \mathrm{~s}$ to $0.5 \mathrm{~s}$. Fig 7 and 8 shows the generation of voltage sag into the system and the compensated voltage waveforms after connecting DVR with PI controller and FLC respectively.

Also, Fig 9 to 11 represents the harmonics generation in system without DVR, with DVR with PI Controller and the same with FLC.

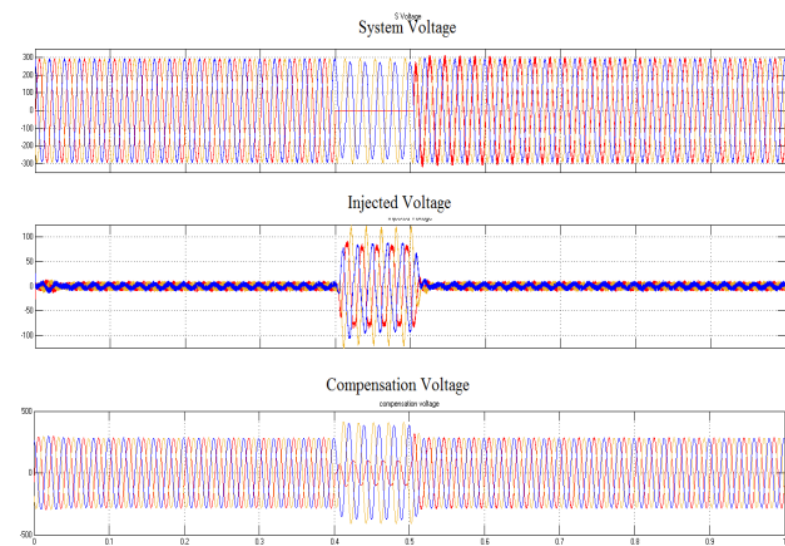

Fig. 7: Voltage Waveforms (DVR with PI Controller) Under L-G Fault. 

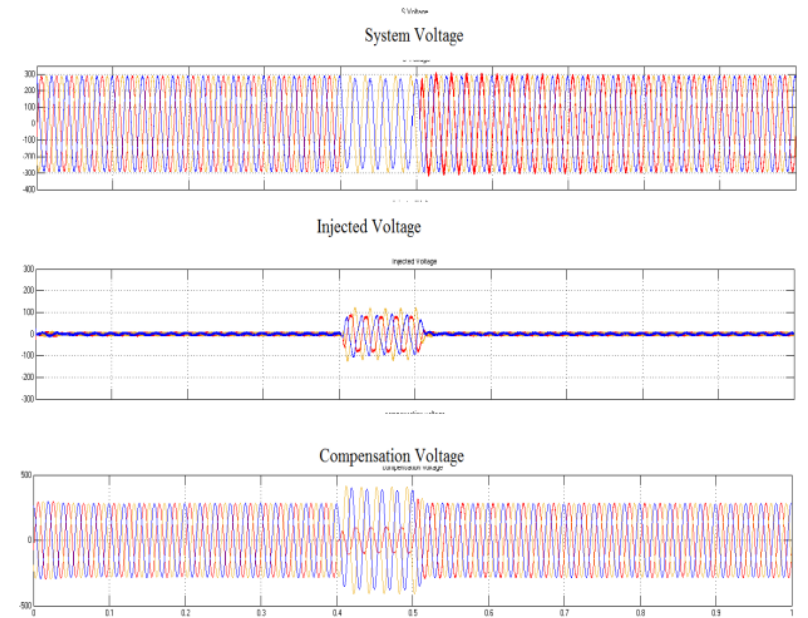

Fig. 8: Voltage Waveforms (DVR with FLC) Under L-G Fault

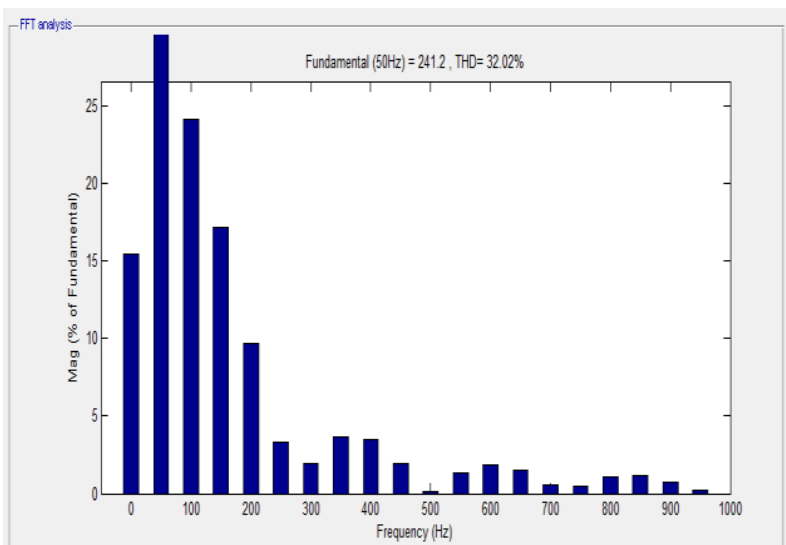

Fig. 9: Harmonics Generation Due To Occurrence of L-G Fault (Withou DVR).

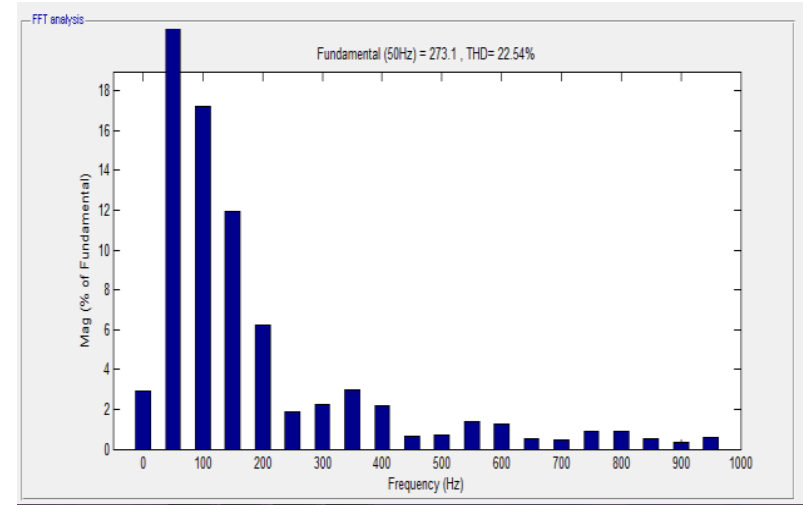

Fig. 10: Harmonics Generation Due to Occurrence of L-G Fault (DVR with PI Controller).

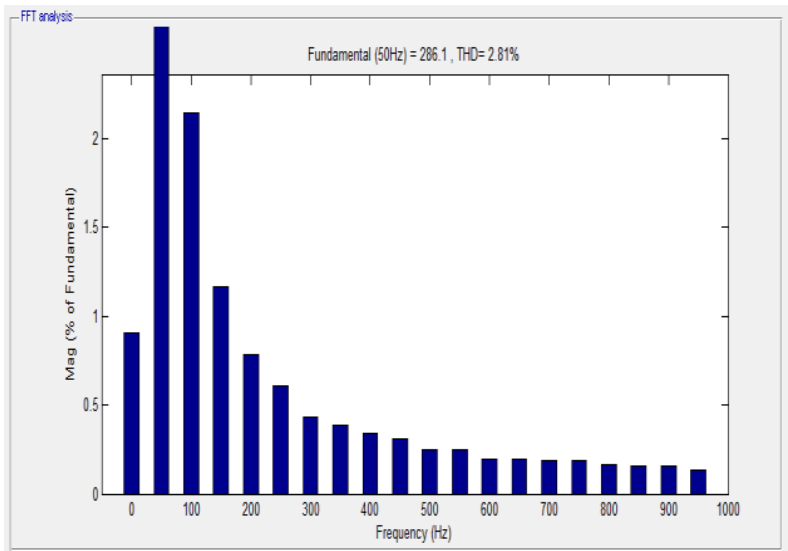

Fig. 11: Harmonics Generation Due to Occurrence of L-G Fault (DVR with FLC).

\section{L-L-G Fault}

Fig 12 and 13 shows the generation of voltage sag into the system and the compensated voltage waveforms after connecting DVR with PI controller and FLC respectively.

Also, Fig 14 to 16 represents the harmonics generation in system without DVR, with DVR with PI Controller and the same with FLC.
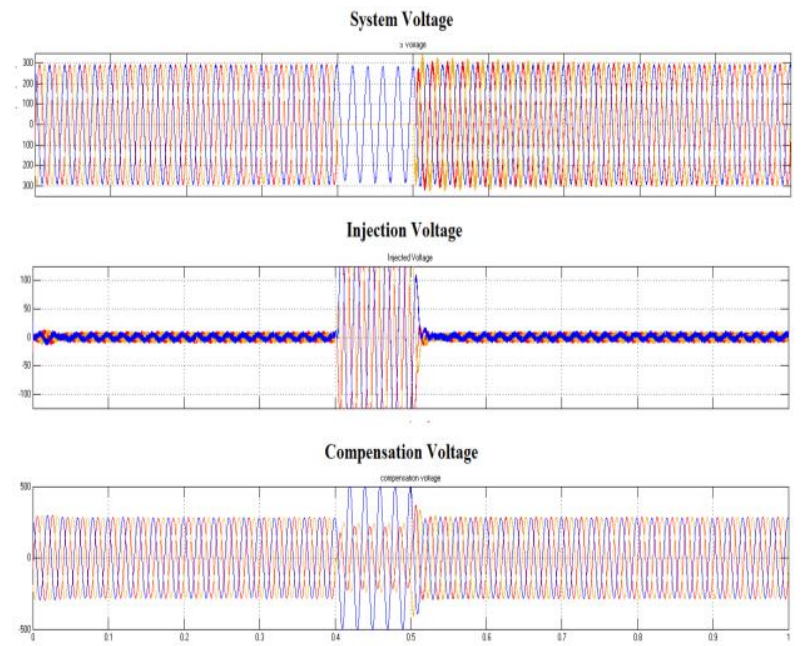

Fig. 12: Voltage Waveforms (DVR with PI Controller) Under L-L-G Fault.
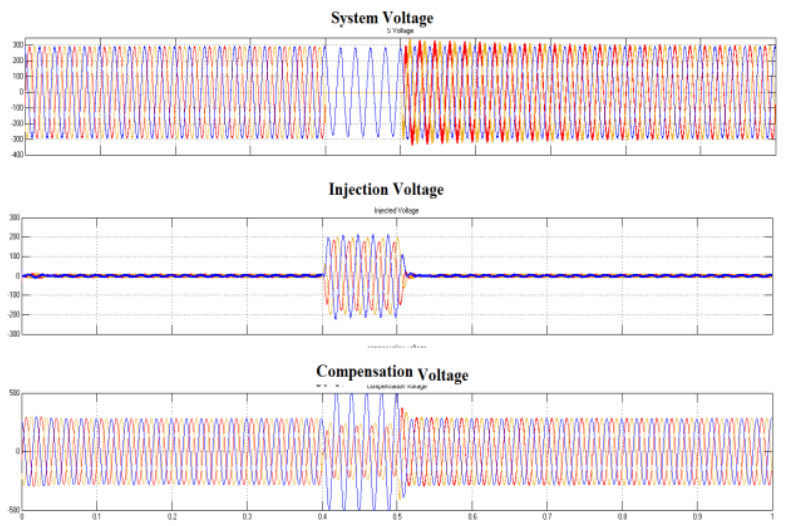

Fig. 13: Voltage Waveforms (DVR with FLC) Under L-L-G Fault

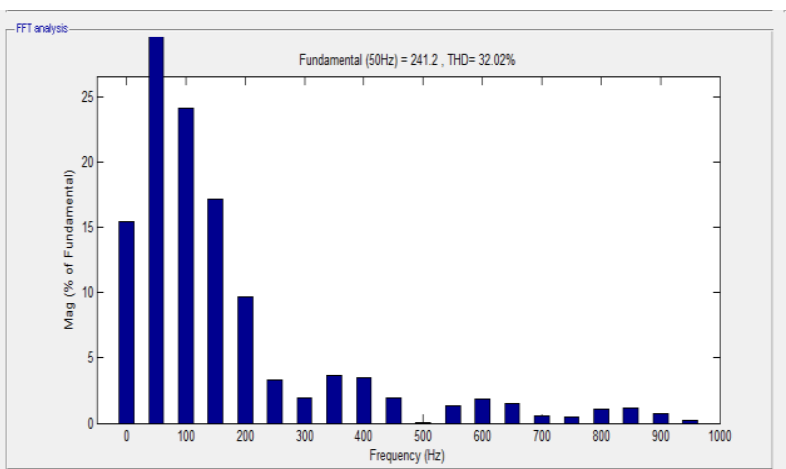

Fig. 14: Harmonics generation due to occurrence of L-L-G fault (without DVR). 


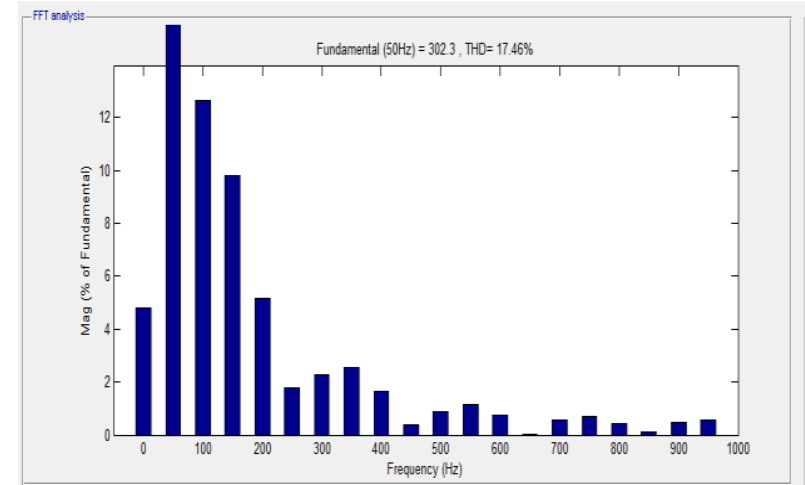

Fig. 15: Harmonics Generation Due To Occurrence Of L-L-G Fault (DVR With PI Controller)

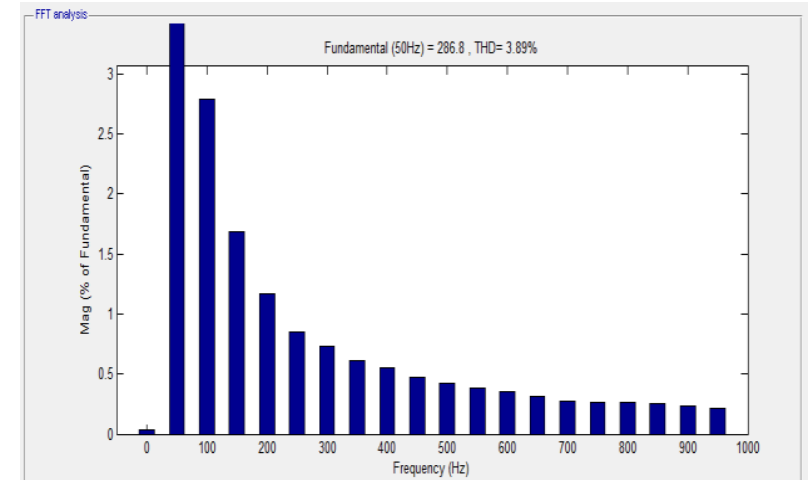

Fig. 16: Harmonics Generation Due to Occurrence of L-L:-G Fault (DVR with FLC).

Similarly, given model is simulated under L-L fault and all the results are shown in Table II for comparison and analysis.

Table 2: Simulation Results

\begin{tabular}{|c|c|c|c|c|c|c|}
\hline \multirow{2}{*}{$\begin{array}{l}\begin{array}{l}\text { Con- } \\
\text { dition }\end{array} \\
\text { Faults }\end{array}$} & \multicolumn{2}{|c|}{ Without DVR } & \multicolumn{2}{|c|}{ DVR (PI) } & \multicolumn{2}{|c|}{ DVR (FLC) } \\
\hline & $\begin{array}{l}\text { Volt- } \\
\text { age } \\
\text { (V) }\end{array}$ & $\begin{array}{l}\text { THD } \\
(\%)\end{array}$ & $\begin{array}{l}\text { Comp. } \\
\text { Voltage } \\
\text { (V) }\end{array}$ & $\begin{array}{l}\text { THD } \\
(\%)\end{array}$ & $\begin{array}{l}\text { Comp. } \\
\text { Voltage } \\
\text { (V) }\end{array}$ & $\begin{array}{l}\text { THD } \\
(\%)\end{array}$ \\
\hline L-G & 241.2 & 32.02 & 273.1 & 22.54 & 286.1 & 2.81 \\
\hline L-L-G & 241.2 & 32.02 & 302.3 & 17.46 & 286.8 & 3.89 \\
\hline L-L & 276.4 & 23.06 & 313.3 & 21.15 & 285.4 & 2.78 \\
\hline
\end{tabular}

*Comp $=$ Compensated.

\section{Conclusion}

On comparing the results, it is observed that the harmonic content in the voltage waveform is decreased to less than $5 \%$ value in case of DVR with FLC. These values are within the limits prescribed by IEEE 519-1992. With reference to this, conclusion leads to:

1) The design of DVR using both PI Controller and FLC proved to be efficient as compared to conventional methods for Power Quality improvement

2) DVR system design with Fuzzy Logic Controller is the best option for electric utility to evaluate, characterize and access the system performance for satisfying the Power Quality needs of distribution system

3) Enforcement of Power Quality standards and Identifying Power Quality problems in an electric power distribution network, before any extensive damage occurs, is advisable.

\section{Acknowledgment}

The project work is being carried out in Bharti Vidyapeeth Deemed University COE, Pune and PES's MCOE, Pune. The authors wish to thank authorities of BVDUCOE, Pune and PES's MCOE, Pune for granting permission to publish the work.

\section{References}

[1] V. S. Jape and D. G. Bharadwaj, "Substation Monitoring System (SMS) For Remote Power Quality Monitoring and Analysis of Power Distribution Network using Object Oriented Web Enabled Method," I J C T A, 10(9), pp. 533-539 ISSN: 0974-5572 @ International Science Press, 2017.

[2] R. Omar and N. A. Rahim, "Implementation and Control of a Dynamic Voltage Restorer using Space Vector Pulse Width Modulation (SVPWM) for Voltage Sag Mitigation," IEEE-TECHPOS, pp-1-6, December 2009.

[3] R. Madhusudan and G. R Rao, "Modeling and Simulation of a Dynamic Voltage Restorer (DVR) for Power Quality Problems- Voltage Sags and Voltage Swells," IEEE- International Conference on Advances in Engineering, Science and Management (ICAESM-2012), pp-442-447, March 2012

[4] N. Prakash and J. Jacob, "Comparison o DVR Performance with Sinusoidal and Space Vector PWM Techniques," International Conference on Magnetics, Machines and Drives, 2014.

[5] M. A. Bhaskar, S. S. Dash, C. Subramani, M. J. Kumar, P.R. Girish and M. V. Kumar, "Voltage Quality improvement using DVR," International Conference on Recent Trends in Information, Telecommunication and Computing, pp.378-380, 2010.

[6] C.H. Raval and A. Doorwar, "An Overview of Various Control Techniques of DVR," ICCPCT, pp-53-57, 2014

[7] D. Szabo, R. Bodnar, M. Regul'a and J. Altus, "Designing and Modeling of DVR in MATLAB," IEEE, 2014.

[8] S. R. Reddy, P. V. Prasad and G. N. Srinivas, "Performance Comparison of DVR by Various Compensation Methods," IEEE, 2014.

[9] B. P. Ganthia, S. Mohanty, P. K. Rana and P. K. Sahu, "Compensation of Voltage Sag using DVR with PI Controller," International Conference on Electrical, Electronics and Optimization Techniques, pp. 2138-2142, 2016

[10] M. Faisal, Alam S Md.., I. M. Md. Arafat, Md. Rahman M., Sk. Md. Mostafa G.: PI Controller and Park's Transformation Based Control of Dynamic Voltage Restorer for Voltage Sag Minimization. International Forum on Strategic Technology, pp.276-279, (2014).

[11] R. Rajeshwari, N. Karpagam and S. Dhanalakshmi, "Analysis of dq0 Based Fuzzy Logic Controller in DVR for Voltage Sag and Harmonic Mitigation," ICGCCE, March 2014.

[12] C. E. Thenmozhi, C. Gopinath and R. Ramesh, "A Novel Method for Voltage Sag / Swell Compensation Using Dynamic Voltage Restorer," IEEE- International Conference on Advances in Engineering, Science and Management, pp. 333-338, 2012.

[13] R. H. Salimin and M. S. A. Rahim, "Simulation Analysis of DVR Performance for Voltage Sag Mitigation," The International Power Engineering and Optimization Conference, pp. 261-266, June 2011.

[14] V. S. Jape and D. G. Bharadwaj, "A New Approach to Object-Oriented Programming Language for Remote Power Quality Monitoring and Analysis Considering Harmonics," International Journal of Artificial Intelligence and Evolutionary Computations in Engineering Systems, Springer India, 2016. 